\title{
Further Comments Regarding Cloud Coding, Recording, and Reporting
}

\author{
William K. Widger, Jr. \\ ARACON Geophysics Company, Concord, Mass. \\ 13 October 1964
}

Portig (1964) has recently discussed the need for revision of the International Cloud Atlas and improvements to present cloud codes and definitions, citing as examples the present insufficiency of nomenclature for the various observed variations in cumulonimbus, especially in the tropics.

An equally vital and perhaps even greater need for cloud nomenclature and code revisions arises from the availability of meteorological satellite data. Such present cloud specifications as:

$\mathrm{C}_{\mathrm{H}^{-}} 5$ Cirrus (often in bands) and Cirrostratus, or Cirrostratus alone, progressively invading the sky; they generally thicken as a whole, but the continuous veil does not reach 45 degrees above the horizon, and

$\mathrm{C}_{\mathrm{H}^{-}} 6$ Cirrus (often in bands) and Cirrostratus, or Cirrostratus alone, progressively invading the sky; they generally thicken as a whole; the continuous veil extends more than 45 degrees above the horizon, without the sky being totally covered.

are among those obviously not appropriate to the observational perspective provided by the satellite.

The problem has been well stated by Erickson and Hubert (1961):

"The use of the synoptic, airways, and pirep codes for reporting and obtaining cloud data entails a certain inevitable loss of information. TIROS represents a new and different observing system, and although the observational language of (most meteorological satellite papers) is largely in terms of the conventionally coded data it is felt that interpretation of cloud type from TIROS pictures should not always be fitted into a classification admittedly inadequate to describe even the limited and discontinuous observations from the ground.
The advantage of the essentially space-continuous TIROS view should be kept in mind. The meso- and synoptic-scale parallel line structure, easily imaged and often seen in TIROS pictures, is an outstanding example of something not categorized within the international cloud classification."

Such studies of cloud types as seen in the satellite pictures as those of Erickson and Hubert (1961) and of Conover $(1962,1963)$ can serve as the foundation for satellite aspects of an international cloud code revision.

It is obvious that a revision of cloud nomenclatures and codes should be of such nature as to be compatible with all common perspectives of observation: from the ground, from aircraft, and from satellites. It should also, of course, eliminate other existing defficiencies, such as those discussed by Portig.

It would seem that an early revision of the International Cloud Allas is definitely worthy of the most serious consideration. Since foreseeable improvements in visible spectrum satellite sensors, such as better resolution, will only provide detail analogous to that presently visible from the ground or from aircraft, expected changes in the nature of the satellite data are not a valid reason for procrastination on this matter.

\section{REFERENCES}

Conover, J. H., 1963: Interpretation of clouds and mesoscale cloud patterns as seen from satellite altitudes. Rocket and Satellite Meleorology, Amsterdam, North Holland Publishing Co., pp. 388-392.

- - 1962, 1963: Cloud interpretation from satellite altitudes (and Supplement 1 thereto). Research Note 81, Air Force Cambridge Research Center, 77 pp. and 19 pp.

Erickson, C. O., and L. F. Hubert, 1961: Identification of cloudforms from TIROS I pictures. Meteorological Satellite Laboratory Report No. 7 , U. S. Weather Bureau, 68 pp.

Portig, W. H., 1964: Notes on the coding and recording of cumulonimbus. J. A ppl. Meteor., 3, 475-478. 